\title{
An Enhanced Drought-Tolerant Method Using SA-Loaded PAMPS Polymer Materials Applied on Tobacco Pelleted Seeds
}

\author{
Yajing Guan, ${ }^{1}$ Huawei Cui, ${ }^{2}$ Wenguang Ma, ${ }^{2}$ Yunye Zheng, ${ }^{2}$ Yixin Tian,, and Jin $\mathrm{Hu}^{1}$ \\ ${ }^{1}$ Seed Science Center, College of Agriculture and Biotechnology, Zhejiang University, Hangzhou 310058, China \\ ${ }^{2}$ Yuxi Zhongyan Tobacco Seed Co., Ltd., Yuxi 653100, China \\ Correspondence should be addressed to Jin Hu; jhu@zju.edu.cn
}

Received 27 April 2014; Revised 12 August 2014; Accepted 12 August 2014; Published 27 August 2014

Academic Editor: Iliya Rashkov

Copyright (c) 2014 Yajing Guan et al. This is an open access article distributed under the Creative Commons Attribution License, which permits unrestricted use, distribution, and reproduction in any medium, provided the original work is properly cited.

\begin{abstract}
Drought is one of the most important stress factors limiting the seed industry and crop production. Present study was undertaken to create novel drought-resistant pelleted seeds using the combined materials with superabsorbent polymer, poly(2-acrylamide-2methyl propane sulfonic acid) (PAMPS) hydrogel, and drought resistance agent, salicylic acid (SA). The optimized PAMPS hydrogel was obtained as the molar ratio of 2-acrylamido-2-methyl-propanesulfonic acid (AMPS) to potassium peroxydisulfate (KPS) and $\mathrm{N}, \mathrm{N}^{\prime}$-methylene-bis-acrylamide (MBA) was 1:0.00046:0.00134. The hydrogel weight after swelling in deionized water for $24 \mathrm{~h}$ reached 4306 times its own dry weight. The water retention ratio (RR) of PAMPS was significantly higher as compared with the control. It could keep as high as $85.3 \%$ of original weight after $30 \mathrm{~min}$ at $110^{\circ} \mathrm{C}$; even at $25^{\circ} \mathrm{C}$ for $40 \mathrm{~d}$, the PAMPS still kept RR at $33.67 \%$. PAMPS disintegration ratio increased gradually and reached around 30\% after embedding in soil or activated sludge for $60 \mathrm{~d}$. In addition, there were better seed germination performance and seedling growth in the pelleted treatments with SA-loaded PAMPS hydrogel under drought stress than control. It suggested that SA-loaded PAMPS hydrogel, a nontoxic superabsorbent polymer, could be used as an effective drought resistance material applied to tobacco pelleted seeds.
\end{abstract}

\section{Introduction}

Tobacco (Nicotiana tabacum L.) originated from tropical and subtropical area with abundant rainfall and high humidity and its water requirement is very high. Most of the tobacco planting regions often lack necessary irrigation facilities; hence, the water deficiency has become the major stress factor with high potential impact on tobacco yield. Seed pelleting technique is a new method of seed treatment. Presently, the planting ratio of tobacco pelleted seeds in china has reached around 90\% [1]. Therefore, research and development on tobacco pelleted seed with drought resistance are of great significance.

So far, a few researches on drought-resistant coating seeds put forward to add some water absorbent into the coating agent [2]. When field irrigation or rainfall comes, the water absorbent could absorb water from the soil to form a small "reservoir," and the stored water will come out of the small "reservoir" to be utilized by the seeds or seedlings when soil is too dry, to achieve drought resistance.
However, the water absorption ratios of traditional water absorbents, such as polyacrylate and acrylic copolymer, were usually in the range from tens to hundreds [3-6]; the limited water absorption capacity could not give full play to the role of the small "reservoir." In addition, it is just a single physical method to improve seed drought resistance, and the water absorbent is difficult to play the role of "reservoir" when there is lack of rainfall or irrigation; the application of coating seeds in arid, semi-arid, or other areas of less rainfall is limited. Therefore, combining the water absorbent and drought-resistant agents to form novel drought-resistant materials is particularly important to ensure the maximum seed germination and seedling establishment under drought stress.

Superabsorbent polymers (SAP) are new functional polymer materials containing strong hydrophilic groups that can absorb and retain extremely large amounts of a liquid relative to their own mass [7]. Based on the characteristics of high water absorption rate and good water retention, they are widely applied in agriculture, forestry, gardening, petroleum 
chemical industry, medical health, environment governance, and other fields $[8,9]$.

2-acrylamide-2-methyl propane sulfonic acid (AMPS) is a kind of multifunctional water-soluble anionic monomer. Due to the molecular structure of unsaturated double bond vinyl and the sulfonic acid functional group with strong anion and hydrophily, AMPS has good performance of polymerization [10] and the water absorption ratio of its polymers; it is known as a superabsorbent resin and can amount the thousands times of its own dry weight in general. The AMPS monomer has been widely applied in the synthesis of water treatment agents, adsorption and separation materials, and water absorbing and retention materials in high efficiency [10]. However, at present, the information on the application of the AMPS monomer on pelleting seeds is lacking in literature.

Salicylic acid (SA) is widely regarded as an endogenous plant growth regulator which plays a significant role in the signal transduction pathway of abiotic stresses in plants [11]. Exogenous SA-induced enhancement in the resistance to drought have been observed in many plants such as maize [12], wheat [13], and rice [14]. In a study, soybean seeds soaking in salicylic acid caused a positive effect on the accumulation of some ions and antagonists, or modifying the inhibitory effect of drought stress [15]. Sharafizad et al. [16] found that wheat seed soaking treatment with SA in low concentration at low level of drought stress could decrease the germination time and increase the germination percentage. However, the effect of SA loaded in superabsorbent polymers on plant drought resistance has not been reported.

The poly(2-acrylamide-2-methyl propane sulfonic acid) (PAMPS) hydrogel was prepared and its synthetic formula was optimized in this study. Owing to high water absorbability and unique three-dimensional network structure, PAMPS hydrogel is considered as a controlled release material by controlling the release of SA from coating agent and further improves the seedling drought tolerance. Therefore, PAMPS hydrogel was used in this study to determine the performance of superabsorbent resin, and SA was used as a droughtresistant chemical that was embedded into PAMPS resin. Then the enhanced drought-resistant effect of the SA-loaded PAMPS hydrogel as coating agent was studied.

\section{Materials and Methods}

2.1. Materials. Tobacco seeds of "Honghua Dajinyuan" (HHDJY) and "MSk326," coating agent (talc and bentonite), and the adhesive were provided by Yunnan Provincial Academy of Tobacco Agricultural Sciences, China. 2Acrylamido-2-methylpropane sulfonic acid (AMPS- ${ }^{+}$) and salicylic acid (SA) were purchased from Shanghai Wing Science and Technology Co., Ltd., Shanghai, China. Potassium persulfate (KPS), N, N'-methylene-bis(acrylamide) (MBA), $\mathrm{NaCl}$, and $\mathrm{NaOH}$ were obtained from Shanghai Dingguo Biotechnology Co., Ltd., Shanghai, China. All chemicals were used as received and experiments were carried out applying double distilled water $\left(\mathrm{ddH}_{2} \mathrm{O}\right)$.
TABLE 1: Preparation of poly(2-acrylamido-2-methylpropane sulfonic acid) (PAMPS) hydrogels.

\begin{tabular}{lccc}
\hline Sample code & AMPS $^{*}(\mathrm{~g})$ & KPS $(\mathrm{g})$ & MBA $(\mathrm{g})$ \\
\hline F1 & 35 & 0.007 & 0.0105 \\
F2 & 35 & 0.007 & 0.0350 \\
F3 & 35 & 0.007 & 0.1050 \\
F4 & 35 & 0.014 & 0.0105 \\
F5 & 35 & 0.014 & 0.0350 \\
F6 & 35 & 0.014 & 0.1050 \\
F7 & 35 & 0.021 & 0.0105 \\
F8 & 35 & 0.021 & 0.0350 \\
F9 & 35 & 0.021 & 0.1050 \\
\hline
\end{tabular}

*AMPS is 2-acrylamido-2-methylpropane sulfonic acid; KPS is potassium persulfate; $\mathrm{MBA}$ is $\mathrm{N}, \mathrm{N}^{\prime}$-methylene-bis(acrylamide).

\subsection{The Synthesis of PAMPS}

2.2.1. The Preparation of Stock Solution. AMPS- $\mathrm{H}^{+}$was crystallized from boiling methanol [17]. 2-Acrylamido-2methylpropane sulfonic acid sodium salt (AMPS- $\mathrm{Na}^{+}$) stock solution was prepared by dissolving $35 \mathrm{~g}$ of $\mathrm{AMPS}-\mathrm{H}^{+}$in $70 \mathrm{~mL}$ of $\mathrm{ddH}_{2} \mathrm{O}$ followed by addition of $15 \mathrm{~mL} 30 \% \mathrm{w} / \mathrm{v}$ $\mathrm{NaOH}$ solution under cooling conditions. Afterwards, the solution was neutralized by titration with $1 \mathrm{M} \mathrm{NaOH}$ to $\mathrm{pH}$ 7.00. Finally, the volume of the solution was adjusted to $100 \mathrm{~mL}$ with $\mathrm{ddH}_{2} \mathrm{O}$.

MBA was crystallized from warm acetone. The MBA stock solution was prepared by dissolving $10.5 \mathrm{~g}$ of MBA in about $90 \mathrm{~mL}$ of $\mathrm{ddH}_{2} \mathrm{O}$ and then adjusting the final volume to $100 \mathrm{~mL}$ with $\mathrm{ddH}_{2} \mathrm{O}$ (the concentration is $0.105 \mathrm{~g} / \mathrm{mL}$ ).

KPS stock solution was prepared by dissolving $0.070 \mathrm{~g}$ of KPS in $10 \mathrm{~mL}$ of $\mathrm{ddH}_{2} \mathrm{O}$ (the concentration is $0.007 \mathrm{~g} / \mathrm{mL}$ ).

For the hydrogel synthesis, $\mathrm{ddH}_{2} \mathrm{O}$ was cooled under nitrogen bubbling.

2.2.2. Synthesis of Hydrogel. The copolymerization of PAMPS hydrogel was carried out in $\mathrm{ddH}_{2} \mathrm{O}$ at $40^{\circ} \mathrm{C}$ in the presence of KPS as the initiator (Table 1). AMPS, MBA, and KPS stock solutions were mixed together according to the ratios in Table 1. After bubbling nitrogen for $20 \mathrm{~min}$, the glass tubes were sealed and immersed in $55^{\circ} \mathrm{C}$ water bath and the polymerization was conducted. The hydrogel would form well after $6 \sim 7 \mathrm{~h}$.

\subsection{The Characteristics of the Hydrogel}

2.3.1. Fourier Transform Infrared Spectroscopy Analysis. Fourier transform infrared spectroscopy (FTIR) was used to characterize the presence of specific chemical groups in the materials. $0.01 \mathrm{~g}$ of PAMPS powder was ground along with $\mathrm{KBr}$ to form a disc and analyzed by using FTIR absorbance mode. FTIR spectra were obtained in the range of wave number from 4000 to $500 \mathrm{~cm}^{-1}$ (Nicolet 5700, Thermo Nicolet, USA). The FTIR spectra were normalized and major vibration bands were associated with chemical groups. 
TABLE 2: The different formulas of tobacco seed pelleting agents.

\begin{tabular}{lccccc}
\hline Treatment & PAMPS $(\mathrm{g})$ & SA $(\mathrm{g})$ & Talc $(\mathrm{g})$ & Bentonite $(\mathrm{g})$ & Total weight $(\mathrm{g})$ \\
\hline Control & 0 & 0 & 70.00 & 30 & 30 \\
P1 & 1.5 & 0 & 68.50 & 30 & 100 \\
P2 & 2.5 & 0 & 67.50 & 30 & 100 \\
S1 & 0 & 0.05 & 69.95 & 30 & 100 \\
S2 & 0 & 0.10 & 69.90 & 30 & 100 \\
S3 & 0 & 0.15 & 69.85 & 30 & 100 \\
P1S1 & 1.5 & 0.05 & 68.95 & 30 & 100 \\
P1S2 & 1.5 & 0.10 & 68.40 & 30 & 100 \\
P1S3 & 1.5 & 0.15 & 68.35 & 30 & 30 \\
P2S1 & 2.5 & 0.05 & 67.45 & 3.40 & 30 \\
P2S2 & 2.5 & 0.10 & 67.35 & 100 \\
P2S3 & 2.5 & 0.15 & & 100 \\
\hline
\end{tabular}

* PAMPS is poly(2-acrylamido-2-methylpropane sulfonic acid) hydrogel (F8) and SA is salicylic acid, tobacco seed pelleting agents with different formulas; the control is the mixture of talc and bentonite without PAMPS hydrogel and SA; P1 and P2 are mixtures of PAMPS hydrogel, talc and bentonite without SA; S1 and S2 are mixtures of SA, talc, and bentonite without PAMPS hydrogel; P1S1, P1S2, P1S3, P2S1, P2S2, and P2S3 are mixtures of SA-loaded PAMPS hydrogel, talc, and bentonite. F8 (shown in Table 1) is the PAMPS hydrogel synthesized by $35 \mathrm{~g}$ of AMPS (2-acrylamido-2-methylpropane sulfonic acid), $0.021 \mathrm{~g}$ of KPS (Potassium persulfate), and $0.035 \mathrm{~g}$ of MBA $\left(\mathrm{N}, \mathrm{N}^{\prime}\right.$-methylene-bis (acrylamide)).

2.3.2. Swelling Measurements in Water and Salt Solutions. $0.03 \mathrm{~g}\left(m_{0}\right)$ of PAMPS powders was accurately weighed and added in air-tight test bottles containing $300 \mathrm{~mL}$ of $\mathrm{ddH}_{2} \mathrm{O}$ or $0.9 \%(w / w) ~ N a C l$ solution. After every 30 min of PAMPS absorbing solution (totally $24 \mathrm{~h}$ ) at room temperature $\left(25^{\circ} \mathrm{C}\right)$, the residues of $\mathrm{ddH}_{2} \mathrm{O}$ or $\mathrm{NaCl}$ solution in the container were filtered with 250 micron nylon mesh filter bag and the PAMPS weight in the swollen state $\left(m_{d}\right)$ was measured. Its weight swelling ratio (SR) was calculated as SR $=\left(\left(m_{d}-\right.\right.$ $\left.\left.m_{0}\right) / m_{0}\right) \times 100 \%(\mathrm{~g} / \mathrm{g})$, where the $m_{0}$ and $m_{d}$ are the weights of the hydrogels in dry state and swollen state for a given time, respectively.

2.3.3. Water Retention Determination. Certain amount $\left(m_{0}\right.$, g) of swollen PAMPS (F8) (24h) was measured in a beaker, and the same weight of water in another beaker was used as a control. Beakers were placed in a chamber at $25^{\circ} \mathrm{C}$ and their weights were measured $\left(m_{d}\right)$ every 5 days (totally $40 \mathrm{~d}$ ) or they were kept in the chambers with different high temperatures $\left(30,50,70,90\right.$ and $\left.110^{\circ} \mathrm{C}\right)$ for $30 \mathrm{~min}$ and then were weighted $\left(m_{d}\right)$. The water retention ratio $(\mathrm{RR})$ at room temperature $\left(25^{\circ} \mathrm{C}\right)$ or high temperatures was calculated as $\mathrm{RR}=\left(m_{d} / m_{0}\right) \times 100 \%(\mathrm{~g} / \mathrm{g})$, where the $m_{0}$ and $m_{d}$ are initial swollen hydrogel weight and weights obtained in a given time at certain temperature, respectively.

2.3.4. PAMPS Disintegration Ratio. Several pots were filled with disinfected soil containing 40\% (w/w) water. A certain amount $\left(m_{0}, \mathrm{~g}\right)$ of dried PAMPS (F8) in the form of bar was embedded in soil and activated sludge. Then the pots were placed in a chamber at $25^{\circ} \mathrm{C}$ for $60 \mathrm{~d}$, and the soil moisture level was maintained at $40 \%$ during the whole period. The PAMPS samples were collected every $10 \mathrm{~d}$, rinsed gently with the $\mathrm{ddH}_{2} \mathrm{O}$ to remove impurities on its surface, and finally dried at $60^{\circ} \mathrm{C}$ to its constant weight $\left(m_{d}\right)$. The PAMPS disintegration ratio $(\mathrm{DR})$ was calculated as $\mathrm{DR}=$ $\left(\left(m_{0}-m_{d}\right) / m_{0}\right) \times 100 \%(\mathrm{~g} / \mathrm{g})$, where the $m_{0}$ and $m_{d}$ are the weight of hydrogel $(\mathrm{g})$ before and after disintegration, respectively.

2.4. Preparation of Seed Coating Agent. The SA-loaded PAMPS hydrogel (F8) was prepared. SA powders (0.05 g (S1), $0.10 \mathrm{~g}(\mathrm{~S} 2)$, and $0.15 \mathrm{~g}(\mathrm{~S} 3))$ were weighted and dissolved in $100 \mathrm{~mL}$ of $\mathrm{dd}_{2} \mathrm{O}$ separately. Next, $1.5 \mathrm{~g}$ (P1) or $2.5 \mathrm{~g}$ (P2) F8 PAMPS powder was added into the above three SA solutions for full swelling and were taken out after $24 \mathrm{~h}$. These SAloaded hydrogels (P1S1, P1S2, P1S3, P2S1, P2S2, and P2S3) were dried at $60^{\circ} \mathrm{C}$ for $48 \mathrm{~h}$ and ground into powder for further use. Eleven seed pelleting agents were prepared in this study according to the formula given in Table 2 .

2.5. Preparation of Tobacco Pelleted Seeds. Two grams of tobacco seeds was first coated with pure water and the above pelleting agents in a cyclic alternating pattern until the seed size reached $1.00 \sim 1.25 \mathrm{~mm}$ diameter $(5 \sim 8 \mathrm{~mL}$ water per gram of naked tobacco seeds sprayed in total); then a second layer of pelleting agents and adhesive solution were supplied cyclically until the seed size was $1.60 \sim 1.80 \mathrm{~mm}$ diameter. All seeds were pelleted by a minitype coater "BY300A" (Shanghai, China) and were air-dried for 2 days at room temperature.

2.6. Seed Germination and Seedling Growth under Drought. Pelleted seeds were placed one by one in each well of the plastic plate, which filled with disinfected soil matrix. Three replications of 100 seeds each for each treatment were used. And drought stress was imposed by adjusting the soil moisture content to $40 \%$ of soil maximum water content. Then, seeds were incubated in a growth chamber (DGX-800E, Safe Experiment Instrument Factory, China) with $250 \mu \mathrm{mol} \cdot \mathrm{m}^{-2} \cdot \mathrm{s}^{-1}$ light intensity and an alternating cycle of $8 \mathrm{~h}$ light at $30^{\circ} \mathrm{C}$ and $16 \mathrm{~h}$ darkness at $20^{\circ} \mathrm{C}$ for 16 days [18]. Since the second day of experiment, the germinated 


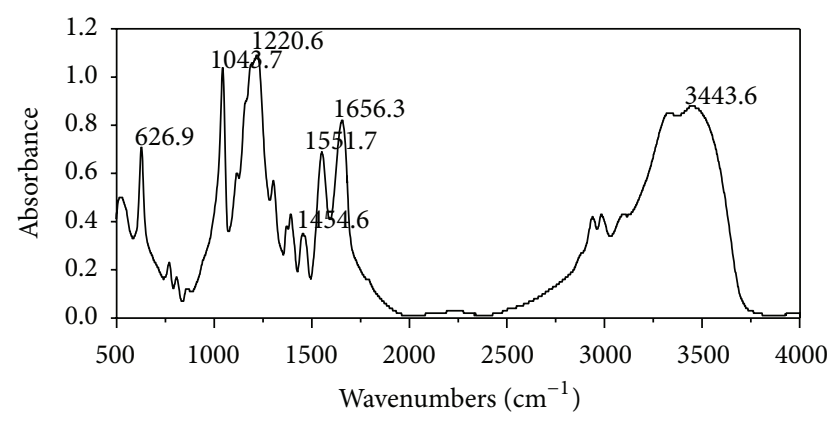

FIGURE 1: FTIR spectrum of PAMPS hydrogel.

seeds were recorded daily for 16 days (standard germination is when the root tip was approximately $1 \mathrm{~mm}$ ). Germination index (GI) and vigor index (VI) were calculated according to $\mathrm{Hu}$ et al. [19] as follows: $\mathrm{GI}=\sum \mathrm{Gt} / \mathrm{Tt}$, where $\mathrm{Gt}$ is the number of the newly germinating seeds in times of $\mathrm{Tt}$; VI = GI $\times$ seedling dry weight. In addition, root length and seedling length were manually measured with a ruler, and seedling dry weight was determined after drying

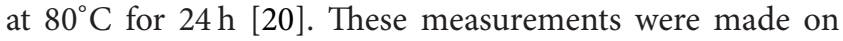
thirty randomly selected normal tobacco seedlings for each replicate [21].

2.7. Statistical Analysis. Statistical analysis of all data was done by means of analysis of variance (ANOVA) using SAS version 8.0 software (SAS Institute, Cary, NC). Fisher's least significant difference (LSD) tests $(P<0.05)$ were adopted for multiple comparison. The percent data were transformed according to $y=\arcsin [\operatorname{sqr}(x / 100)]$ before ANOVA.

\section{Results}

3.1. Fourier Transform Infrared Spectroscopy Analysis of PAMPS. A typical spectrum of PAMPS copolymer was shown in Figure 1. The characteristic absorption peak of AMPS units was shown at $1220.6 \mathrm{~cm}^{-1}$ due to the $\mathrm{S}=\mathrm{O}$ group. The peak was shown at $1043.7 \mathrm{~cm}^{-1}$ due to the sulfonic acid groups. The amide I peak at $1656.3 \mathrm{~cm}^{-1}$ ( $\mathrm{C}=\mathrm{O}$ stretching) and amide II peak at $1551.7 \mathrm{~cm}^{-1}$ (N-H bending vibration) were ascribed to the amide bond of PAMPS. The $\mathrm{N}-\mathrm{H}$ stretching peak was shown at $3443.6 \mathrm{~cm}^{-1}$.

3.2. The Liquid Absorption Performance. After $24 \mathrm{~h}$ liquid swelling, weight swelling ratios (SR) of nine PAMPS hydrogels were shown in Figure 2. Based on $35 \mathrm{~g}$ AMPS and $0.0105 \mathrm{~g}$ MBA, no matter how much KPS was applied, F1, F4, and F7 had lower weight swelling ratios in water and salt solution compared with other prepared PAMPS hydrogels; meanwhile, there were no significant differences among these three hydrogels. However, F2, F5, and F8, after increasing the amount of MBA to $0.0350 \mathrm{~g}$, had higher SRs than other PAMPS hydrogels; and their SRs increased obviously with the increasing of KPS amount when water is used as a swelling medium. In addition, it was worth noting that the SRs of PAMPS hydrogels (F3, F6, and F9) turned to decline if too much MBA $(0.105 \mathrm{~g})$ were added into the polymerized system, and their SRs decreased quickly as the KPS amount increased.

The PAMPS polymerized according to the F8 formula in Table 1 had the highest SR in water and reached 4306 times its own dry weight. Its SR in salt solution was 373, which was a little lower than the SR of F2 and F5 PAMPS. Thus, the F8 PAMPS was chosen to determine the change of weight swelling ratio along with the increasing of liquid absorption time at $25^{\circ} \mathrm{C}$ (Figure 3). The SR of F8 PAMPS in water and salt solution increased obviously and reached more than 4000 and 350 times its own dry weight, respectively, after $3 \mathrm{~h}$. In addition, the weight swelling rates during the first $30 \mathrm{~min}$ of liquid absorption were evidently faster than other time periods.

3.3. The Water Retention Properties. The water retention properties of PAMPS hydrogel (F8) were tested under room temperature $\left(25^{\circ} \mathrm{C}\right.$ ) (Figure 4$)$ and higher temperatures (Figure 5). The results showed that the water retention ratio (RR) of PAMPS (F8) at a given time was always higher than that of control at $25^{\circ} \mathrm{C}$. Compared with the $6.6 \%$ of original weight of control after $40 \mathrm{~d}$, the F8 PAMPS hydrogel could keep the RR as high as $33.67 \%$ (Figure 4). Even treated under $110^{\circ} \mathrm{C}$ for $30 \mathrm{~min}$, the PAMPS still kept RR at $85.3 \%$ (Figure 5).

3.4. The Disintegration Characteristic. The F8 PAMPS disintegration ratio (DR) increased gradually as the time went on (Figure 6). After embedding in soil and activating sludge for $60 \mathrm{~d}$, the PAMPS disintegration ratio was $29.5 \%$ and $35 \%$, respectively. Moreover, except for $20 \mathrm{~d}$, The F8 PAMPS hydrogel had higher DR in activated sludge than in soil.

3.5. Changes of Seed Germination and Seedling Growth under Drought Condition. For both of tobacco varieties, except S1 and S3, other nine treatments significantly improved the seed germination under drought stress compared with the control (Table 3). All of the GP, GI, and VI of P2S3 had the highest value in the above nine pelleting treatments, especially for HHDJY. For MSk326, except the GP of P2S3 which was a little lower than that of P2S2, the GI and VI were still higher than other treatments.

No significant differences were found in root length (RL), seedling length (SL), and dry weight (SDW) among the treatments with $\mathrm{P} 1, \mathrm{P} 2, \mathrm{~S} 1$, and the control in both of tobacco varieties (Tables 4 and 5). However, three treatments with $2.5 \mathrm{~g}$ of PAMPS loaded with SA (P2S1, P2S2, and P2S3) in HHDJY and four treatments (P1S3, P2S1, P2S2, and P2S3) in MSk326 significantly improved the RL, SL, SFW, and SDW as compared with the control, and the most pronounced effect was recorded in P2S3. In addition, seed pelleted with S3 inhibited significantly the seedling growth compared with the control and other treatments irrespective of variety.

\section{Discussions}

In this study, the best super absorbent PAMPS hydrogel according to $1: 0.00046: 0.00134(\mathrm{~mol} / \mathrm{mol} / \mathrm{mol})$ ratios of the 

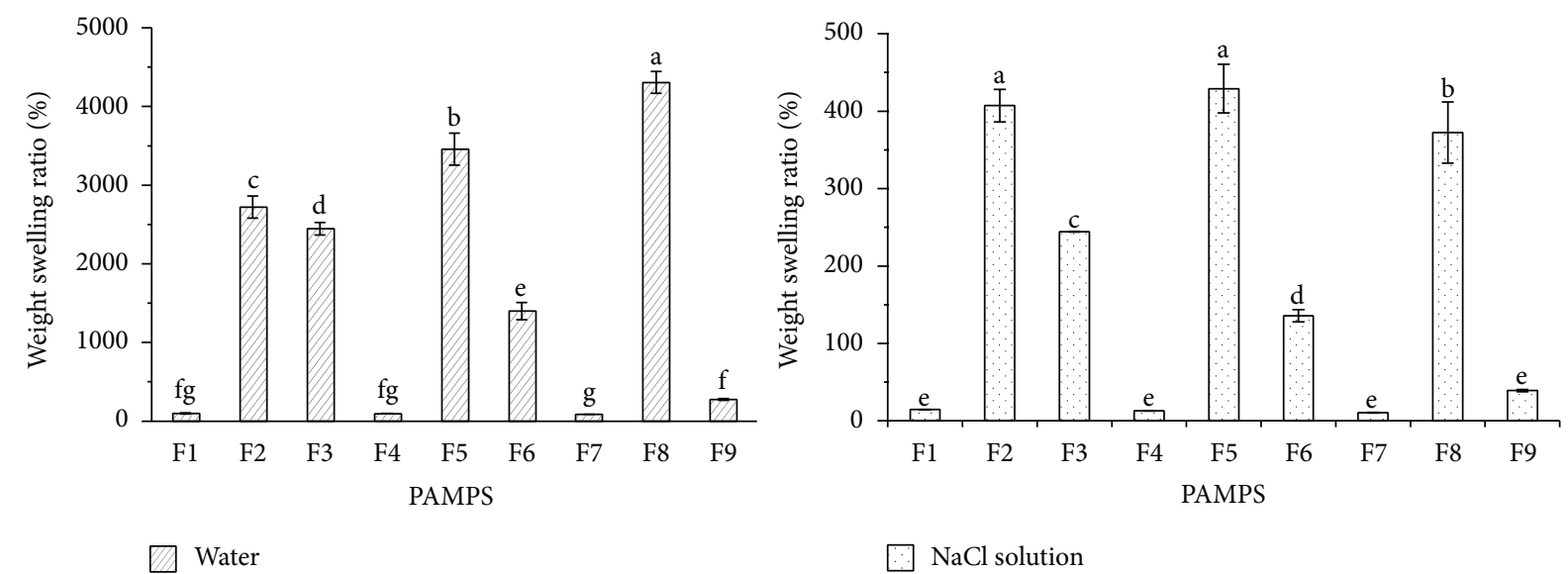

FIGURE 2: Weight swelling ratios of PAMPS hydrogels in water and salt solution for $24 \mathrm{~h}$ at $25^{\circ} \mathrm{C}$. Lowercased letters mean significant difference $(\mathrm{a}=0.05, \mathrm{LSD})$ among different PAMPS hydrogels. The formulas of different PAMPS hydrogels are shown in Table 1. Error bars represent \pm S.E.
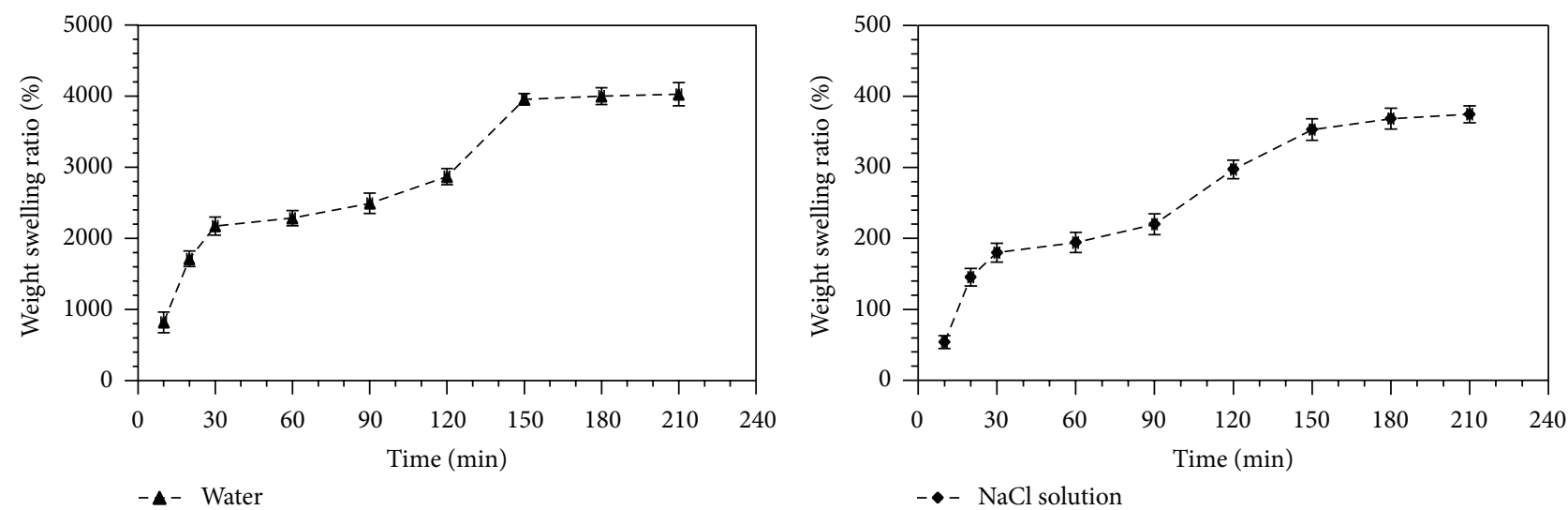

FIGURE 3: Weight swelling kinetics of F8 PAMPS polymers in water and salt solution at $25^{\circ} \mathrm{C}$. F8 (shown in Table 1) is the PAMPS hydrogel synthesized by $35 \mathrm{~g}$ of AMPS (2-acrylamido-2-methylpropane sulfonic acid), $0.021 \mathrm{~g}$ of KPS (potassium persulfate), and $0.035 \mathrm{~g}$ of MBA (N, $\mathrm{N}^{\prime}$-methylene-bis(acrylamide)). Error bars represent \pm S.E.

TABLE 3: Effects of different coating agents on tobacco pelleting seed germination under drought stress.

\begin{tabular}{|c|c|c|c|c|c|c|}
\hline \multirow{2}{*}{ Treatment $^{\mathrm{b}}$} & \multicolumn{3}{|c|}{ HHDJY } & \multicolumn{3}{|c|}{ MSk326 } \\
\hline & GP (\%) & GI & VI & GP (\%) & GI & VI \\
\hline Control & $54.2 c^{a}$ & $2.84 \mathrm{c}$ & $47.21 \mathrm{c}$ & $52.3 \mathrm{c}$ & $2.73 c$ & $43.30 \mathrm{~d}$ \\
\hline $\mathrm{P} 1$ & $63.4 \mathrm{~b}$ & $3.38 \mathrm{~b}$ & $56.77 \mathrm{~b}$ & $62.5 \mathrm{ab}$ & $3.32 \mathrm{~b}$ & $54.02 \mathrm{c}$ \\
\hline $\mathrm{P} 2$ & $66.7 \mathrm{~b}$ & $3.55 \mathrm{~b}$ & $59.74 \mathrm{~b}$ & $63.4 \mathrm{ab}$ & $3.41 \mathrm{~b}$ & $55.67 \mathrm{c}$ \\
\hline S1 & $56.7 \mathrm{c}$ & $2.92 \mathrm{c}$ & $50.68 c$ & $50.7 \mathrm{c}$ & $2.81 \mathrm{c}$ & $40.05 \mathrm{~d}$ \\
\hline S2 & $64.7 \mathrm{~b}$ & $3.45 \mathrm{~b}$ & $58.21 \mathrm{~b}$ & $63.3 \mathrm{~b}$ & $3.41 \mathrm{~b}$ & $57.26 \mathrm{bc}$ \\
\hline S3 & $40.7 \mathrm{~d}$ & $2.13 \mathrm{~d}$ & $38.86 \mathrm{~d}$ & $43.3 \mathrm{e}$ & $2.25 \mathrm{~d}$ & $40.79 \mathrm{e}$ \\
\hline P1S1 & $70.8 \mathrm{ab}$ & $3.79 \mathrm{ab}$ & $65.35 \mathrm{~b}$ & $65.3 \mathrm{ab}$ & $3.48 \mathrm{ab}$ & $56.81 \mathrm{c}$ \\
\hline P1S2 & $70.8 \mathrm{ab}$ & $3.89 \mathrm{ab}$ & $66.61 \mathrm{ab}$ & $65.7 \mathrm{ab}$ & $3.55 \mathrm{ab}$ & $57.96 \mathrm{bc}$ \\
\hline P1S3 & $67.6 \mathrm{~b}$ & $3.66 \mathrm{~b}$ & $62.96 \mathrm{~b}$ & $65.3 \mathrm{ab}$ & $3.43 \mathrm{~b}$ & $57.38 \mathrm{bc}$ \\
\hline $\mathrm{P} 2 \mathrm{~S} 1$ & $71.8 \mathrm{ab}$ & $3.85 \mathrm{ab}$ & $66.76 \mathrm{ab}$ & $63.9 \mathrm{~b}$ & $3.43 \mathrm{~b}$ & $57.16 \mathrm{bc}$ \\
\hline $\mathrm{P} 2 \mathrm{~S} 2$ & $72.2 \mathrm{ab}$ & $3.93 \mathrm{ab}$ & $68.08 \mathrm{ab}$ & $68.1 \mathrm{a}$ & $3.68 \mathrm{ab}$ & $61.66 \mathrm{ab}$ \\
\hline $\mathrm{P} 2 \mathrm{~S} 3$ & $73.6 \mathrm{a}$ & $4.07 \mathrm{a}$ & 71.11 a & $67.1 \mathrm{ab}$ & $3.70 \mathrm{a}$ & $63.32 \mathrm{a}$ \\
\hline
\end{tabular}

GP: germination percentage; GI: germination index; VI: vigor index.

${ }^{a}$ Lowercased letters mean significant difference $(\mathrm{a}=0.05$, LSD) among treatments within the same variety.

${ }^{\mathrm{b}}$ For additional explanations, see Table 2. 
TABLE 4: Effects of coating agents on seedling growth of Honghuadajinyuan (HHDJY) under drought stress.

\begin{tabular}{lcccc}
\hline Treatment $^{\mathrm{b}}$ & RL $(\mathrm{mm})$ & SL $(\mathrm{mm})$ & SFW (mg/30 plants) & SDW (mg/30 plants) \\
\hline Control & $8.02 \mathrm{c}^{\mathrm{a}}$ & $15.75 \mathrm{~b}$ & $141.5 \mathrm{~b}$ & $15.84 \mathrm{c}$ \\
P1 & $8.66 \mathrm{bc}$ & $16.80 \mathrm{ab}$ & $147.8 \mathrm{~b}$ & $16.68 \mathrm{bc}$ \\
P2 & $8.87 \mathrm{bc}$ & $16.82 \mathrm{ab}$ & $150.4 \mathrm{ab}$ & $16.86 \mathrm{bc}$ \\
S1 & $8.13 \mathrm{c}$ & $15.66 \mathrm{~b}$ & $146.5 \mathrm{~b}$ & $15.57 \mathrm{c}$ \\
S2 & $9.15 \mathrm{ab}$ & $16.80 \mathrm{ab}$ & $154.3 \mathrm{ab}$ & $17.40 \mathrm{ab}$ \\
S3 & $7.56 \mathrm{~d}$ & $14.38 \mathrm{c}$ & $130.9 \mathrm{c}$ & $14.85 \mathrm{~d}$ \\
P1S1 & $9.10 \mathrm{ab}$ & $17.22 \mathrm{a}$ & $157.5 \mathrm{a}$ & $17.49 \mathrm{ab}$ \\
P1S2 & $8.93 \mathrm{bc}$ & $17.12 \mathrm{a}$ & $154.5 \mathrm{ab}$ & $16.65 \mathrm{bc}$ \\
P1S3 & $9.16 \mathrm{ab}$ & $17.19 \mathrm{a}$ & $153.0 \mathrm{ab}$ & $17.34 \mathrm{ab}$ \\
P2S1 & $9.13 \mathrm{ab}$ & $17.34 \mathrm{a}$ & $158.3 \mathrm{a}$ & $17.49 \mathrm{ab}$ \\
P2S2 & $9.17 \mathrm{ab}$ & $17.34 \mathrm{a}$ & $161.3 \mathrm{a}$ & $17.64 \mathrm{ab}$ \\
P2S3 & $9.38 \mathrm{a}$ & $17.46 \mathrm{a}$ & $17.85 \mathrm{a}$ \\
\hline
\end{tabular}

RL: root length; SL: seedling length; SFW: seedling fresh weight; SDW: seedling dry wight.

${ }^{a}$ Lowercased letters mean significant difference $(a=0.05, \mathrm{LSD})$ among treatments within the same variety.

${ }^{\mathrm{b}}$ For additional explanations, see Table 2.

TABLE 5: Effects of coating agents on seedling growth of MSk326 under drought stress.

\begin{tabular}{lcccc}
\hline Treatment $^{\mathrm{b}}$ & RL $(\mathrm{mm})$ & SL $(\mathrm{mm})$ & SFW (mg/30 plants) & SDW (mg/30 plants) \\
\hline Control & $7.55 \mathrm{c}^{\mathrm{a}}$ & $14.38 \mathrm{c}$ & $130.9 \mathrm{c}$ & $15.09 \mathrm{c}$ \\
P1 & $8.39 \mathrm{bc}$ & $16.28 \mathrm{bc}$ & $139.7 \mathrm{~b}$ & $16.14 \mathrm{c}$ \\
P2 & $8.42 \mathrm{bc}$ & $16.34 \mathrm{bc}$ & $142.0 \mathrm{~b}$ & $16.26 \mathrm{c}$ \\
S1 & $7.50 \mathrm{c}$ & $14.45 \mathrm{c}$ & $132.7 \mathrm{c}$ & $16.05 \mathrm{c}$ \\
S2 & $8.41 \mathrm{bc}$ & $16.31 \mathrm{bc}$ & $141.8 \mathrm{~b}$ & $16.74 \mathrm{~b}$ \\
S3 & $7.02 \mathrm{~d}$ & $13.56 \mathrm{~d}$ & $119.6 \mathrm{~d}$ & $14.19 \mathrm{~d}$ \\
P1S1 & $8.48 \mathrm{bc}$ & $16.31 \mathrm{bc}$ & $149.3 \mathrm{~b}$ & $15.99 \mathrm{c}$ \\
P1S2 & $8.49 \mathrm{bc}$ & $16.32 \mathrm{bc}$ & $151.5 \mathrm{ab}$ & $16.80 \mathrm{~b}$ \\
P1S3 & $8.78 \mathrm{~b}$ & $150.8 \mathrm{ab}$ & $17.10 \mathrm{ab}$ \\
P2S1 & $8.85 \mathrm{ab}$ & $16.73 \mathrm{ab}$ & $150.8 \mathrm{ab}$ & $17.04 \mathrm{ab}$ \\
P2S2 & $8.83 \mathrm{ab}$ & $16.65 \mathrm{ab}$ & $17.40 \mathrm{a}$ \\
P2S3 & $9.16 \mathrm{a}$ & $16.78 \mathrm{ab}$ & $158.3 \mathrm{a}$ & $17.40 \mathrm{a}$ \\
\hline
\end{tabular}

RL: root length; SL: seedling length; SFW: seedling fresh weight; SDW: seedling dry weight.

${ }^{a}$ Lowercased letters mean significant difference $(a=0.05$, LSD) among treatments within the same variety.

${ }^{\mathrm{b}}$ For additional explanations, see Table 2.

AMPS monomer to KPS and MBA was prepared. It is worth noting that when appropriate MBA was applied, the liquid absorption ratio of PAMPS could be improved by increasing KPS; however, it would be inhibited after improper amount of BMA was used. The results suggested that MBA played an important role in the preparation of PAMPS hydrogels having less or more density network, which is responsible for the swelling degree of the obtained hydrogels. Also, Nalampang et al. [22] found the significant influence of crosslink density (MBA) on water content of AMPS-based hydrogels.

The major FTIR absorption peaks of the PAMPS were consistent with related reports [17] and there was no other impurity peaks. It was reasonable to conclude that the PAMPS was polymerized successfully according to the synthesis route. The water absorption ratio could reach as much as 4306 times its own dry weight, which was far higher than other materials such as keratin-based hydrogel [3], polyacrylic acid sodium salt [4], and starch-based superabsorbent [6].
It might be because the linear polymers with sulfonate groups derived from AMPS exhibit extensive coil expansion in aqueous solutions, even in a $5 \mathrm{M} \mathrm{NaCl}$ solution [17]. In addition, due to the strongly ionizable sulfonate group, AMPS dissociates completely in the overall $\mathrm{pH}$ range, and the hydrogels derived from AMPS exhibit $\mathrm{pH}$ independent swelling behavior [23]. Thus, the prepared PAMPS hydrogel in this study was supposed to be able to adapt to various $\mathrm{pH}$ conditions. However, it still warrants further study.

PAMPS exhibited slow disintegration characteristic in soil; two months later, about one-third of PAMPS weight degraded and eventually broke down for nitrogen dioxide, water, ammonia nitrogen, and sodium ion, and so forth. That meant it was nontoxic and environmentally safe to be used [24]. Meanwhile, the above characteristic of PAMPS enhanced its valid period and efficiency in practice. Up to now, productions of super absorbent polymers in China have been widely used in food crops, economic crops, vegetables, 


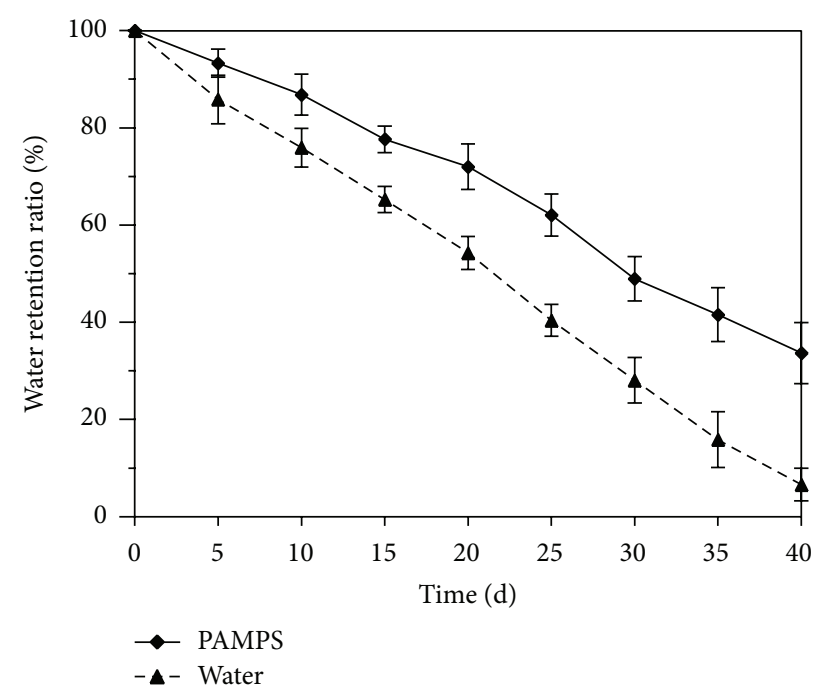

Figure 4: Water retention kinetics of F8 PAMPS polymer at $25^{\circ} \mathrm{C}$. Error bars represent \pm S.E. For additional explanations, see Figure 3 .

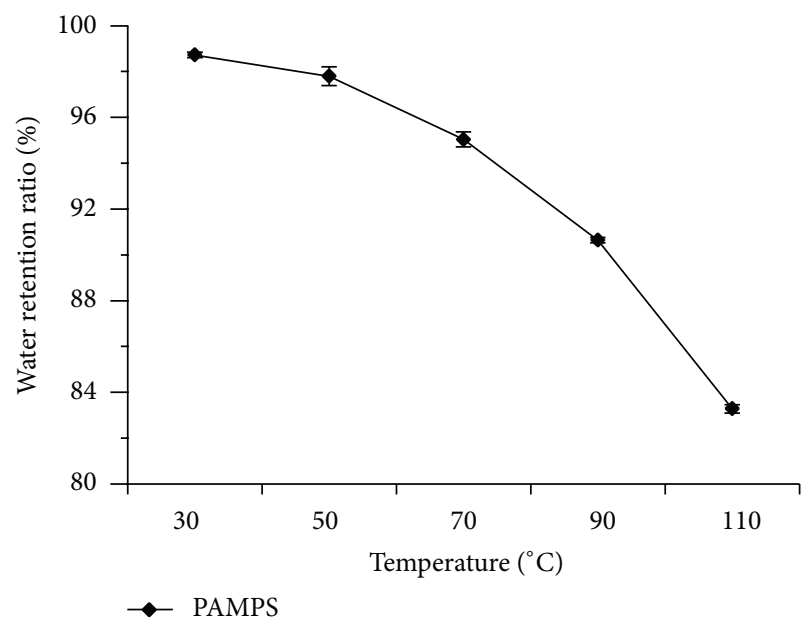

FIGURE 5: Water retention ratios of F8 PAMPS polymer at different temperature for $30 \mathrm{~min}$. Error bars represent \pm S.E. For additional explanations, see Figure 3.

flowers, fruit trees, lawn cultivation, and so forth and proved to be effective [24].

However, it was still unclear whether the PAMPS was suitable for pelleting or could enhance tobacco seed drought resistance as a small "reservoir" without interference of coating agents. Therefore, studying the effects of different coating agents including PAMPS on tobacco seedling establishment was necessary. The results showed that the PAMPS alone (P1 and P2) could improve the seed germination and seedling growth under drought, even the increase of seed GP, GI, and VI reached a significant level as compared with the control. It suggested that the moisture absorbed by polymer from soil could be used gradually at stages of seedling growth. The similar results were also reported in soybean seed coated with starch-grafting super absorbent resin [2] and maize seed

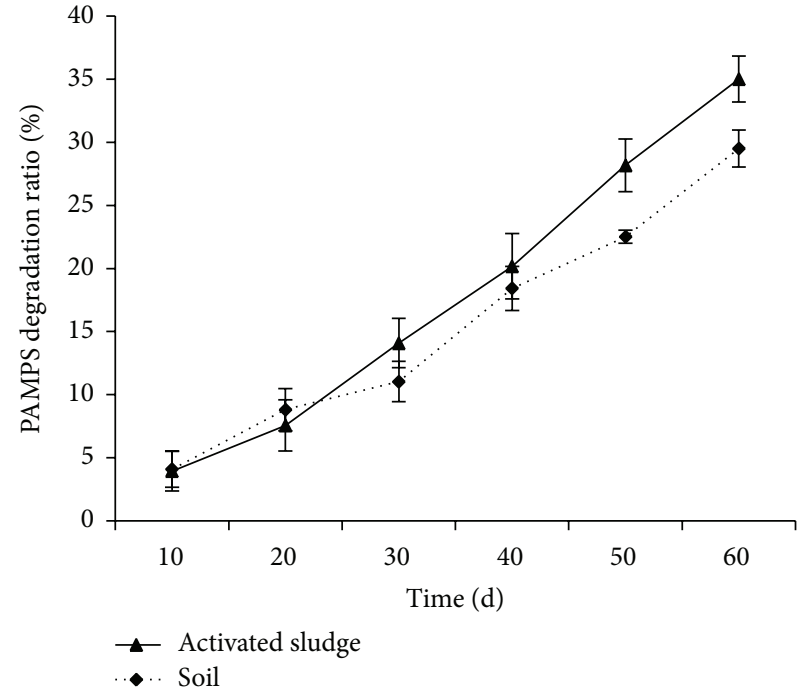

FIGURE 6: F8 PAMPS polymer disintegration ratio versus time histories in soil and activated sludge. Error bars represent \pm S.E. For additional explanations, see Figure 3.

coated with polyacrylic acid sodium high water absorbent polymer [25].

Moreover, the P2S3, $2.5 \mathrm{~g}$ PAMPS loaded with $0.15 \mathrm{~g} \mathrm{SA}$, was proved to be the best coating agent formula for tobacco seed pelleting. The positive effect of SA-loaded PAMPS on seed germination and seedling growth under drought stress was better than that of the SA or PAMPS alone. Salicylic acid improves germination by neutralizing free radicles or active oxygen; however, it was important to note that $0.15 \mathrm{~g} \mathrm{SA}$ alone had an obvious inhibition on seedling growth; however, after loading the same amount of SA into PAMPS, P1S3 and $\mathrm{P} 2 \mathrm{~S} 3$ distinctly turned to improve the seed germination. This might be due to the high concentration of SA that negatively influences the plant growth via inhibiting the activities of protective enzymes and promoting MDA production [26]. Meanwhile, the PAMPS hydrogel might have the controlled effect on SA release to some extent to ensure the lower effective concentration instead of the higher inhibiting concentration.

In addition, it suggested that the likely reasons for drought tolerance obtained by tobacco pelleting seeds with PAMPS coating agents were as follows: one was that more than $85 \%$ water absorbed by super absorbent polymer was considered to be effective to the plant. Like a miniature reservoir, as the rhizosphere soil moisture changed, PAMPS could absorb and release water repeatedly to supply for plant roots utilization [27]. Another study showed that the soil structure was improved via PAMPS application, which contributed to the improvement of soil porosity and air permeability [28, 29]. Su et al. [30] reported that as a result of water in the soil absorbed by hydrogel, soil thermal conductivity, and temperature difference between day and night reduced, which would be good for the crop growth.

In this study, PAMPS was used not only as superabsorbent polymer but also as SA controlled release material that was 
given full play to the dual-use value of PAMPS. On the one hand, water released from PAMPS improved tobacco seedling establishment under drought; on the other hand, the SA loaded in the PAMPS would be controlled released to further enhance the seedling drought resistance.

\section{Conclusions}

In practice, with the special "reservoir" characteristic, the SAloaded PAMPS hydrogel represents a potential dual-effect on improvement of tobacco seed and seedling drought tolerance. This seed pelleting method with enhanced drought-resistant function may become a novel pathway to enhance seed establishment under stresses. However, this method still should be verified in other crop seeds; or there should be an upgrade to this method with different chemicals to implement in plant resistance against stresses.

\section{Conflict of Interests}

The authors declare that there is no conflict of interests regarding the publication of this paper.

\section{Authors' Contribution}

Yajing Guan and Huawei Cui contributed equally to this work.

\section{Acknowledgments}

The research was supported by Project of Yunnan Provincial Tobacco Company (nos. 2013YN10 and 2011YN10), the National Natural Science Fund (nos. 31201279 and 31371708), Special Fund for Agro-Scientific Research in the Public Interest (no. 201203052), and Project of Science and Technology Department of Zhejiang Province (no. 2013C32023), China.

\section{References}

[1] W. G. Ma, Y. Y. Zheng, Y. P. Li, Y. Z. Niu, and Y. S. Chen, "Effects of water priming duration and different drying methods of pelleted seed on germination of tobacco pelleted seeds and seedling growth," Acta Agriculturae Jiangxi, vol. 21, no. 7, pp. 2931, 2009.

[2] Z. Y. Wang, Z. X. Liu, and Y. C. Wei, "Effects of super absorbent polymers coating on photosynthesis and water use efficiency of soybean," Agriculture Research in the Arid Area, vol. 22, no. 3, pp. 105-108, 2004.

[3] J. M. Cardamone, "Keratin sponge/hydrogel II: active agent delivery," Textile Research Journal, vol. 83, no. 9, pp. 917-927, 2013.

[4] X. Dang, Y. Zhang, and Y. Huang, "Modeling of the effect of super absorbent polymer on soil moisture," Transactions of the Chinese Society of Agricultural Engineering, vol. 21, no. 4, pp. 191192, 2005.

[5] X. H. Zhou, L. W. Liao, and A. H. Shi, "Synthesis study for AAHEMA copolymer super absorbents of high anti-salt," Journal of Guangdong Industry Technical College, vol. 4, no. 1, pp. 16-19, 2005.
[6] Y. Zhao and S. Jiang, "Effect of porosity generators on absorbency rate starch-based superabsorbent," Transactions of the Chinese Society of Agricultural Machinery, vol. 40, no. 10, pp. 126-128, 2009.

[7] F. Nnadi and C. Brave, "Environmentally friendly superabsorbent polymers for water conservation in agricultural lands," Journal of Soil Science and Environmental Management, vol. 2, no. 7, pp. 206-211, 2011.

[8] S. Francis, M. Kumar, and L. Varshney, "Radiation synthesis of superabsorbent poly(acrylic acid)-carrageenan hydrogels," Radiation Physics and Chemistry, vol. 69, no. 6, pp. 481-486, 2004.

[9] L. M. Hansen, D. J. Smith, D. H. Reneker, and W. Kataphinan, "Water absorption and mechanical properties of electrospun structured hydrogels," Journal of Applied Polymer Science, vol. 95, no. 2, pp. 427-434, 2005.

[10] E. Nadim, F. Ziaee, H. Bouhendi, and A. Askarizadeh, "Stereocontrol study in radical polymerization of 2-acrylamido-2methylpropane sulfonic acid in the presence of lewis acids," Journal of Macromolecular Science A: Pure and Applied Chemistry, vol. 48, no. 7, pp. 526-530, 2011.

[11] E. Horváth, G. Szalai, and T. Janda, "Induction of abiotic stress tolerance by salicylic acid signaling," Journal of Plant Growth Regulation, vol. 26, no. 3, pp. 290-300, 2007.

[12] A. Gunes, A. Inal, M. Alpaslan, F. Eraslan, E. G. Bagci, and N. Cicek, "Salicylic acid induced changes on some physiological parameters symptomatic for oxidative stress and mineral nutrition in maize (Zea mays L.) grown under salinity," Journal of Plant Physiology, vol. 164, no. 6, pp. 728-736, 2007.

[13] E. Horváth, M. Pál, G. Szalai, E. Páldi, and T. Janda, "Exogenous 4-hydroxybenzoic acid and salicylic acid modulate the effect of short-term drought and freezing stress on wheat plants," Biologia Plantarum, vol. 51, no. 3, pp. 480-487, 2007.

[14] M. Farooq, S. M. A. Basra, A. Wahid, N. Ahmad, and B. A. Saleem, "Improving the drought tolerance in rice (Oryza sativa L.) by exogenous application of salicylic acid," Journal of Agronomy and Crop Science, vol. 195, no. 4, pp. 237-246, 2009.

[15] A. M. A. Al-Hakimi, "Counteraction of drought stress on soybean plants by seed soaking in salicylic acid," International Journal of Botany, vol. 2, no. 4, pp. 421-426, 2006.

[16] M. Sharafizad, A. Naderi, S. A. Siadat, T. Sakinejad, and S. Lak, "Effect of salicylic acid pretreatment on germination of wheat under drought stress," Journal of Agricultural Science, vol. 5, no. 3, pp. 179-199, 2013.

[17] S. Durmaz and O. Okay, "Acrylamide/2-acrylamido-2methylpropane sulfonic acid sodium salt-based hydrogels: synthesis and characterization," Polymer, vol. 41, no. 10, pp. 3693-3704, 2000.

[18] ISTA, International Rules for Seed Testing, International Seed Testing Association, Bassersdorf, Switzerland, 2010.

[19] J. Hu, Z. Y. Zhu, W. J. Song, J. C. Wang, and W. M. Hu, "Effects of sand priming on germination and field performance in directsown rice (Oryza sativa L.)," Seed Science and Technology, vol. 33, no. 1, pp. 243-248, 2005.

[20] C. F. Zhang, J. Hu, J. Lou, Y. Zhang, and W. M. Hu, "Sand priming in relation to physiological changes in seed germination and seedling growth of waxy maize under high-salt stress," Seed Science and Technology, vol. 35, no. 3, pp. 733-738, 2007.

[21] S. Xu, J. Hu, Y. Li, W. Ma, Y. Zheng, and S. Zhu, "Chilling tolerance in Nicotiana tabacum induced by seed priming with putrescine," Plant Growth Regulation, vol. 63, no. 3, pp. 279-290, 2011. 
[22] K. Nalampang, N. Suebsanit, C. Witthayaprapakorn, and R. Molloy, "Design and preparation of AMPS-based hydrogels for biomedical use as wound dressings," Chiang Mai Journal of Science, vol. 34, no. 2, pp. 183-189, 2007.

[23] O. Okay and S. Durmaz, "Charge density dependence of elastic modulus of strong polyelectrolyte hydrogels," Polymer, vol. 43, no. 4, pp. 1215-1221, 2001.

[24] Z. Wang, Research on Seed Coating of Four Pasture Seeds, Jilin University, 2006.

[25] H. W. Chen, S. T. Jiang, J. Q. Zhou, Y. Y. Zhao, and J. H. Wang, "Super absorbent polymer seed coating and its effect on physiological features of corn seed," Journal of Hefei University of Technology (Natural Science), vol. 27, no. 3, pp. 242-246, 2004.

[26] C. J. Cai, S. N. Chen, M. Yin, H. C. Zhou, and Q. Wang, "Effects of salicylic acid on some enzyme activities related to stress resistance and content of MDA in Vanilla planifolia," Acta Botanica Yunnanica, vol. 25, no. 6, pp. 700-704, 2003.

[27] Y. Liu, J. J. Xie, and X. Y. Zhang, "Synthesis and some properties of the copolymer of acrylamide with 2-acrylamido2-methylpropane sulfonic acid," Journal of Applied Polymer Science, vol. 90, no. 13, pp. 3481-3487, 2003.

[28] J. Lin, J. L. Ke, H. Z. Liu, and W. J. Hu, "Effects of super water absorbent resin on the physical properties of eroded soil," Journal of Fujian Agricultural and Forestry University (Natural Science Edition), vol. 31, no. 2, pp. 259-265, 2002.

[29] G. J. Geng, G. S. Bai, S. N. Du, J. Yu, and M. Li, "Effects of super absorbent with different application methods on soil moisture, soil salinity and Lycopersicon esculentum growth," Science of Soil and Water Conservation, vol. 9, no. 3, pp. 65-70, 2011.

[30] W. Q. Su, L. Yang, and D. M. Yang, "Effects of super water absorbent on soil improvement," Journal of Northeast Forestry University, vol. 32, no. 5, pp. 35-41, 2004. 


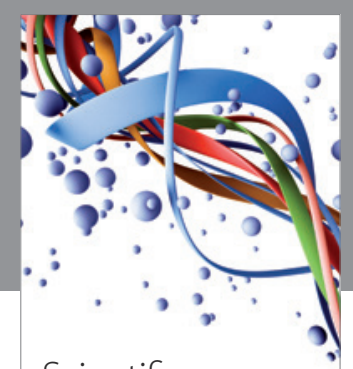

Scientifica
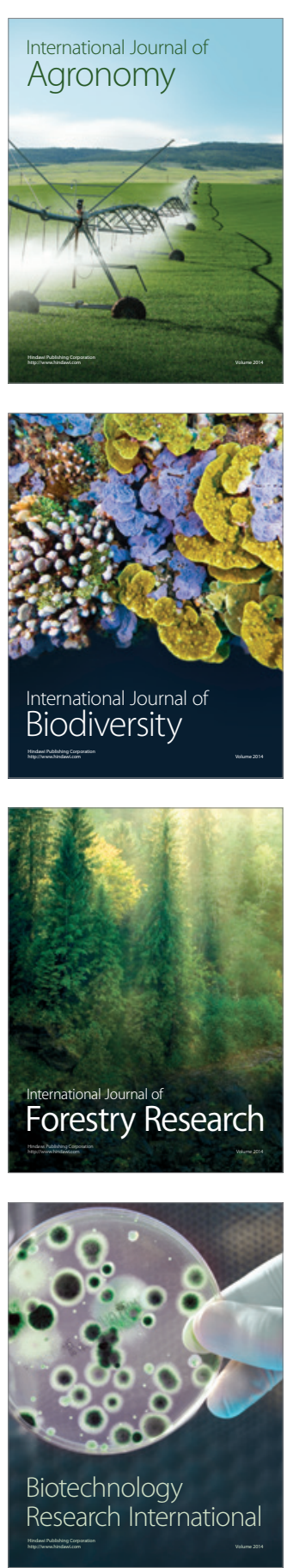
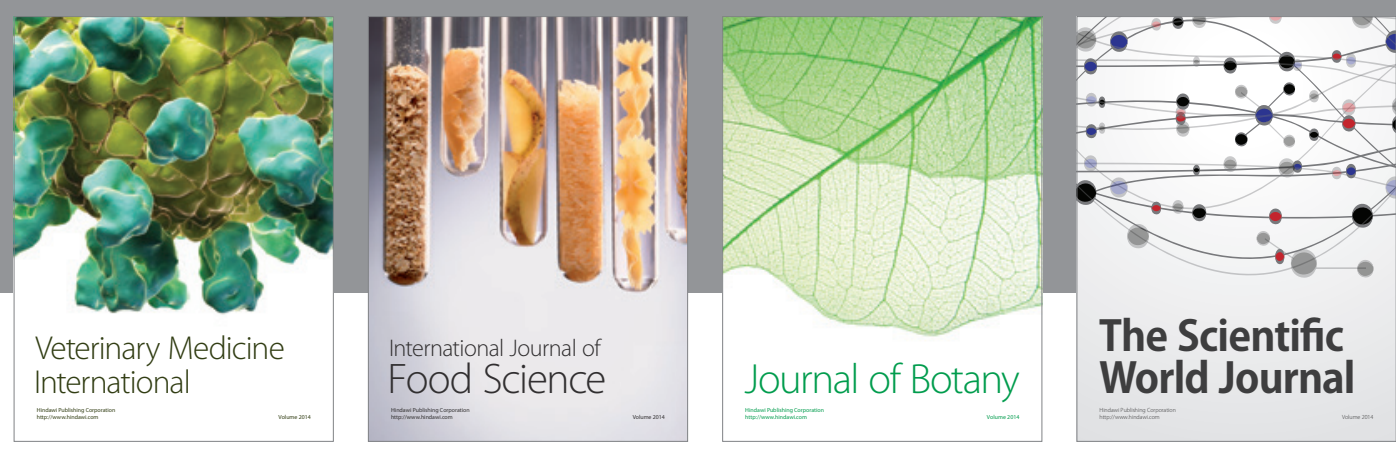

The Scientific World Journal
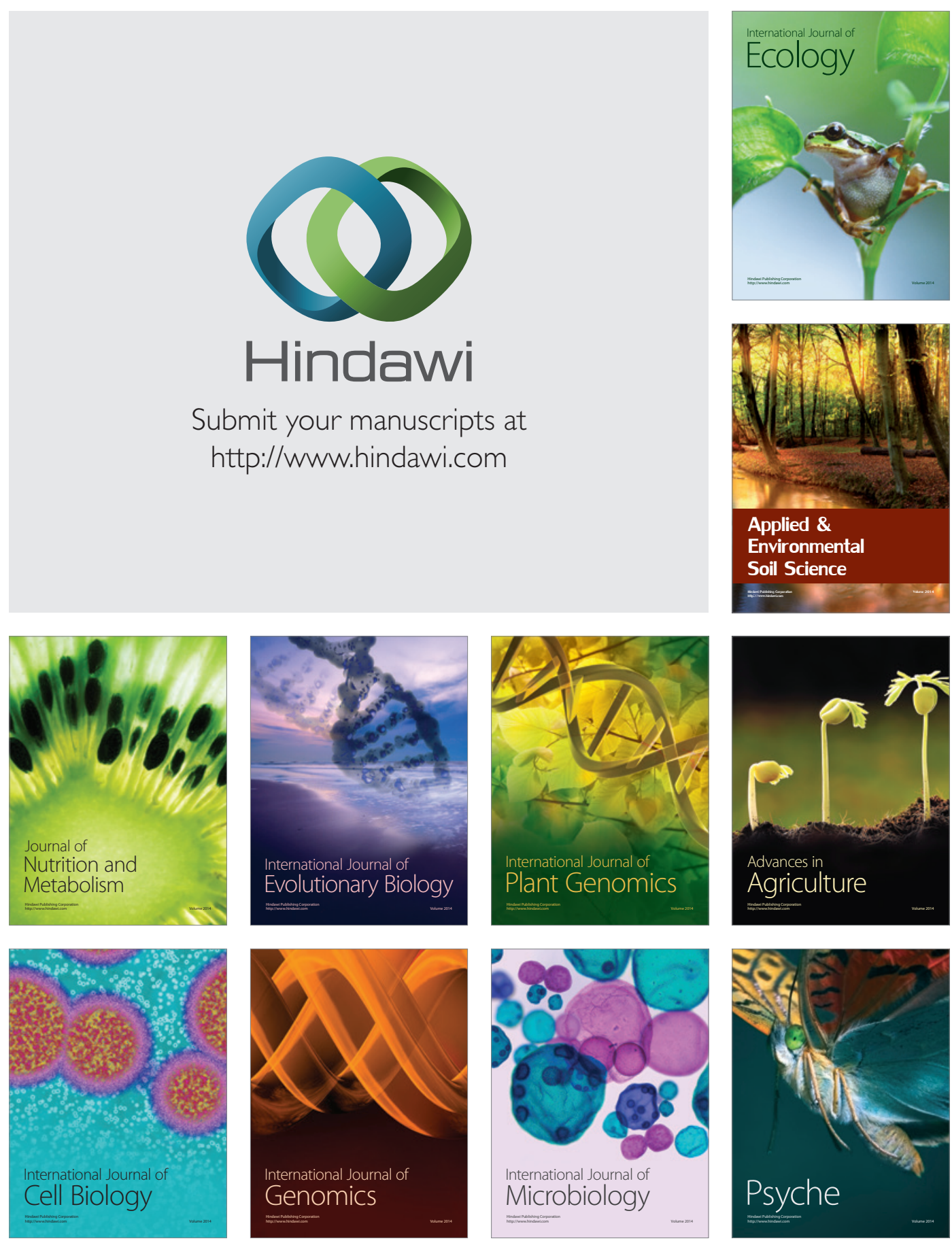